\title{
Experimental and Theoretical Investigation of Water Jet Pump Performance
}

\author{
W.A.Aissa \\ Professor, \\ Mechanical Power Eng. Dept., \\ Faculty of Energy Engineering \\ Aswan University \\ Aswan, Egypt \\ waessa@aswu.edu.eg
}

\author{
M.Shaban.Eissa \\ Lecturer, Mechanical Power Eng. Dept., \\ Faculty of Energy Engineering \\ Aswan University \\ Aswan, Egypt \\ mshaban68@yahoo.com
}

\author{
Amr Hamza Hassan Mohamed \\ High Dam Power Station. \\ Hydro Plant Generation Company, \\ Aswan, Egypt \\ amrhamza1980@gmail.com
}

\begin{abstract}
- in this paper, we've experimentally and theoretically (analytical and numerical) investigated the water jet pump. The effect of operational and geometrical parameters on the water jet pump efficiency were determined experimentally and theoretically. Experimental investigation was held 'firstly to work out the effect of driving nozzle spacing, area ratio, diffuser angle and throat length on the performance of water jet pump. A test rig has been designed to examine the jet pump various parts using different dimensions and shapes. A MAT LAB computer program has been designed supported the derived formula and theoretical loss factors for all parts of the jet pump. the consequences of adjusting area ratio on the performance of jet pump are investigated employing a Computational Fluid Dynamic (CFD) analysis with ANSYS FLUENT software The CFD analysis reveals that changing jet pump performance are often achieved by changing jet pump area ratio. The experimental results are compared with the analytical investigation and therefore the comparison indicates an honest agreement between them
\end{abstract}

Keywords— jet pump; analytical; loss factors; CFD simulation

\section{INTRODUCTION}

A jet pump is a device that utilizes momentum transfer action from a high velocity jet fluid to pump another fluid, either an equivalent or different from that of the jet. There are two kinds of jet pumps supported different primary and secondary fluid input arrangements. the primary type is that the central jet pump, which applies the first fluid to the inner nozzle and connects the annular periphery-surrounding the nozzle with the secondary fluid. The other is that the annular jet pump, during which the suction fluid passes through the inner nozzle and therefore the primary fluid is connected with the annular nozzle on the periphery of the suction tube. CFD simulation may be a lower cost, reliable, and straightforward to use method as compared with experimentation; it allows numerous repetitions of the tests requiring a smaller work area, less time, and personnel that creates it a superior simulation technique. this contemporary technique also provides the likelihood of performing modifications within the design with less expense and time, by easily analyzing the flow field or physical details of flow, and achieving an improvement in, and optimization of the planning. This study is divided into two

main parts. The first part is an experimental test on a jet pump under different conditions like inlet motive pressure, nozzle spacing, area ratio, diffuser angle, and throat length. The area ratio was also numerically modeled by using the Computational Fluid Dynamic. the other a part of the study was to perform The MATLAB program was designed supported the derivative formula and theoretical loss factors for the jet pump. The Experimental results were compared with theoretical results Comparison indicated good agreement between experimental and theoretical results.

\section{NOMENCLATURE}

$A$

$D$

$g$

H

K

$L$

$M$

$N$

$P$

$Q$

$R$

$S P$

V

X

$\alpha$

$\varepsilon$

$\boldsymbol{\varepsilon}$

$\chi$

$\kappa$

Subscrip

di Diffuser

en Secondary inlet

$i \quad$ Inlet

$n \quad$ Nozzle

$s \quad$ Suction

td Throat-diffuser

th Throat

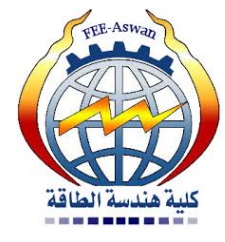




\section{Test Rig DESCRIPTION AND MEASURING INSTRUMENT}

A. Experimental Apparatus

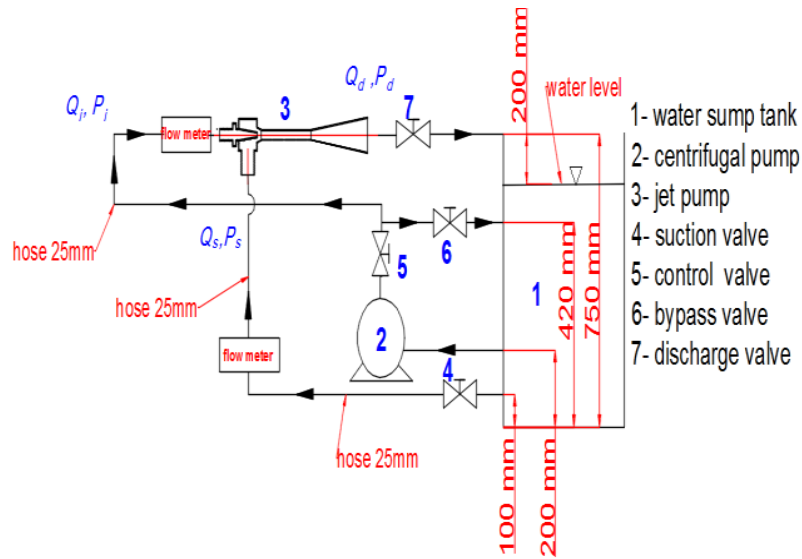

Fig. 1. Experimental test rig

B. A schematic description of the experimental setup is presented in Figure 1. The experimental apparatus consists of a $120 \mathrm{~L}$ storage tank (1) for water supply, pump (2), Jet pump (3) with different parts. a suction valve (4), and a control valve (5) to regulate the pump inlet pressure, bypass valve (6), discharge valve (7). The test rig may be a closed-loop system process where water is pumped from the storage tank to the jet pump nozzle via a $25.4 \mathrm{~mm}$ inner diameter hose fitted with an impact valve for controlling the motive pressure. A bypass valve (6) is employed to regulate the motive flow to the jet pump. The pump operating head and rate of flow $32 \mathrm{~m}$ and from $70 \mathrm{l} / \mathrm{min}$ respectively. Water from the suction tank (1) is lifted up by the jet pump towards the suction chamber then, towards the mixing chamber. then, the water passes through the diffuser towards the tank.

\section{Measuring Instrument}

The water flow rates is measured using Ultrasonic flowmeter, while the motive, delivery and suction pressures of the jet pump are measured using Digital pressure indicator calibrator. The instrument are show in fig. 2

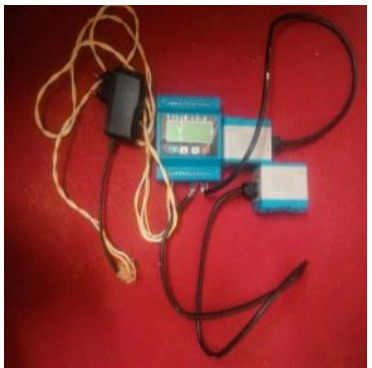

a) Ultrasonic flow meter

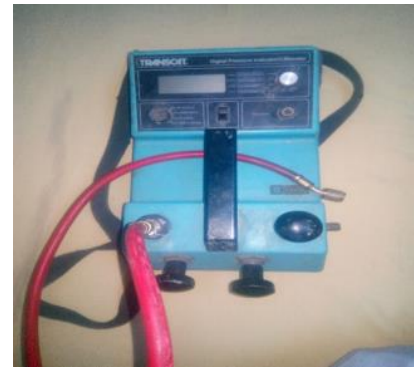

b) Digital pressure indicator/calibrator
Fig. 2. Measuring instrument

\section{JET PUMP ANALYSIS}

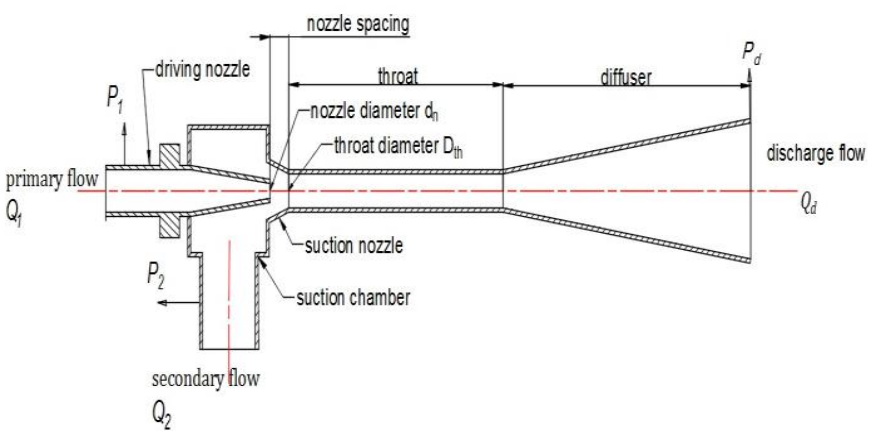

Fig. 3. jet pump elements

Figure 3 show jet pump elements, the performance of jet pump is generally considered to be a function of the parameters defined as follows:

\section{A. Flow ratio $(M)$}

It is the ratio between suction flow rate and primary flow rate of the jet pump.

$\mathrm{M}=\mathrm{Q}_{\mathrm{S}} / \mathrm{Q}_{\mathrm{i}}$

\section{B. Head Ratio $(N)$}

It is the ratio between net jet pump head and net driving head of the jet pump.

$\mathrm{N}=\left(\mathrm{H}_{\mathrm{d}}-\mathrm{H}_{\mathrm{s}}\right) /\left(\mathrm{H}_{\mathrm{i}}-\mathrm{H}_{\mathrm{d}}\right)$

Where

$\mathrm{H}_{\mathrm{i}}=\mathrm{P}_{\mathrm{i}} / \gamma+\left(\mathrm{V}_{\mathrm{i}}^{\wedge} 2\right) / 2 \mathrm{~g}+\mathrm{Z}$

$\mathrm{H}_{\mathrm{d}}=\mathrm{P}_{\mathrm{d}} / \gamma+\left(\mathrm{V}_{\mathrm{d}}^{\wedge} 2\right) / 2 \mathrm{~g}+\mathrm{Z}_{\mathrm{d}}$

$\mathrm{H}_{\mathrm{s}}=\mathrm{P}_{\mathrm{s}} / \gamma+\left(\mathrm{V}_{\mathrm{s}} \wedge 2\right) / 2 \mathrm{~g}+\mathrm{Z}_{\mathrm{s}}$

\section{Jet pump Efficiency ( $\eta)$}

It is defined as the ratio of energy increase of suction stream (output energy) to the energy decrease of driving stream (input energy).

$\eta=M^{*} N$

\section{Other calculated parameters}

(X) Ratio of nozzle-to-throat spacing to throat diameter

$\mathrm{X}=\mathrm{SP} / \mathrm{D}_{\text {th }}$

(R) Area ratio

$\mathrm{R}=\mathrm{A}_{\mathrm{n}} / \mathrm{A}_{\mathrm{th}}$ 


\section{EXPERIMENTAL PROCEDURE}

The experimental procedure applied in this study to determine the jet pump performance when changing the design of water jet pump is detailed below:

1- Water temperature and atmospheric pressure are recorded.

2- The water tank is filled with fresh water and kept at constant water level.

3- Assemble jet pump parts.

4- The centrifugal pump is turned on, and valve (5) is gradually opened and the discharge valve (7) is fully closed.

5- The pump pressure is adjusted to one bar and then the jet pump discharge valve was gradually opened until the flow is reversed in suction line.

6- When a steady state condition was attained; the motive, delivery and suction pressures of the jet pump are measured and inlet, suction and discharge flow rates are recorded.

7- The discharge valve (7) is partially opened until it is fully opened; the procedure is repeated every time the discharge valve was opened.

8- Motive pressures are change from one bar to 2.5 bars with step 0.5 bars, and steps (4 to 7) are repeated with different motive fluid pressure.

9- The jet pump is changed with different design dimension and steps (4) to (8) are repeated.

\section{TESTS, RESUlTS AND DisCUSSION}

\section{A. Effect of Nozzle-to-throat Spacing to throat diameter} ratio; $X$

The position of the nozzle has a great effect on jet pump performance. In the current paper four driving nozzle spacing $\mathrm{SP}=0,8,16$ and $24 \mathrm{~mm}$. and throat diameter $\mathrm{D}_{\mathrm{th}}=16 \mathrm{~mm}$. This give equivalent ratio; $X=0,0.5,1$ and 1.5. Figures 4 and 5 present the performance curves of water jet pump. The results show the effects of flow ratio and driving pressure on the jet pump efficiency. It is evident from the figure that as the head ratio decreases. The efficiency increases. The curves present a parabolic form with little asymmetry. The maximum pump efficiency obtained for nozzle-to-throat spacing to throat diameter ratio $\mathrm{X}=$ one and driving pressure of $\mathrm{P}=2.5$ bar is about $16 \%$ at a flow ratio of 1.1 . Whereas for $\mathrm{P}=$ one bar the maximum efficiency is $13 \%$ at a flow ratio of one. This indicated a little reduction in jet pump efficiency. Typical results of the pump performance was obtained for nozzle-tothroat spacing to nozzle diameter ratio $\mathrm{X}=0.0,0.5,1.0$ and 1.5. In all cases, the maximum head ratio of the pump is obtained at a driving pressure of one bar. In addition, Figures 4 and 5 show, the flow ratio is inversely proportional to the head ratio. For nozzle-to-throat spacing to throat diameter ratio $\mathrm{X}=$ one, it is found that, the maximum head ratio of the jet pump is obtained for a drive pressure of one bar which is 0.30 head ratio at a flow ratio of 0.2 and the minimum head ratio is 0.11 which corresponds to a flow ratio of 0.90 .

\section{B. Effect of Area Ratio; $R$}

The area ratio is the most important design element of the jet pump in this study, three different throats with different diameters of 16,13 and $11 \mathrm{~mm}$ are used in combination with one constant driving nozzle diameter of $7 \mathrm{~mm}$, which gives three area ratios of $0.19,0.29$ and 0.41 . Figures 6 and 7 show the effect of changing area ratio on the performance of water jet pump under the following conditions: throat diameter and length 16 and $155 \mathrm{~mm}$ respectively and diffuser angle $5^{\circ}$. Is clear from this figure for the same jet pump combination parts and increasing the area ratio the efficiency and the head ratio increase. The efficiency increases also with increasing the flow ratio. The highest values of efficiency and head ratio are for area ratio of 0.19 at $\mathrm{X}=$ one. It is also clear that the area ratio of 0.19 gives the best performance compared to 0.41 area ratio, which gives the lower efficiency. This may be owing to that the jet pump with area ratio of 0.19 draws more driving fluid than that with 0.41 area ratio for the same driving pressure.

\section{Effect of Mixing Chamber Length; $L_{t h}$}

In this study, four throat lengths of 80, 120, 155 and $180 \mathrm{~mm}$ with $16 \mathrm{~mm}$ diameter. The dimensionless throat length ratios are 5.00, 7.50, 9.69 and 11.25 respectively. Figure 8 and 9 show the results of the effect of changing throat length $\mathrm{L}_{t h}$ on the performance of water jet pump for the following configuration: area ratio $\mathrm{R}=0.19$ and diffuser angle $\alpha_{\mathrm{d}}=5^{\circ}$. It is clear from the figure that the throat length of $155 \mathrm{~mm}$ has more efficiency over 80,120 and $180 \mathrm{~mm}$ for all experiments done. The differences in jet pump efficiency using the four different throat lengthes is shown in Figures 8 and 9. The superiority in the performance of $155 \mathrm{~mm}$ throat length provides a suitable environment to the mixing process to be completed. This means that the suction fluid extracts more power from the driving fluid. The performance of jet pump having longer mixing length is penalized by friction losses in the throat. In addition, the shorter throat length resultes in continuation of mixing into diffuser with associated performance loss.

\section{Effect of Changing Diffuser Angle; $\alpha_{d}$}

In the current paper three diffuser angles $\alpha_{d}$ of $3^{\circ}, 5^{\circ}$ and $8^{\circ}$ with lengths $\mathrm{L}_{\mathrm{di}}$ of $180 \mathrm{~mm}$, the inlet diameters of the diffusers are $18 \mathrm{~mm}$. Figures 10 and 11 illustrate the results of the effect of changing diffuser angle $\alpha_{\mathrm{d}}$ on the performance of water jet pump for the following configuration: area ratio of 0.19 and throat diameter and length of 16 and $155 \mathrm{~mm}$ respectively at $\mathrm{X}=1$. It is clear from a figure that the diffuser angle of $\alpha \mathrm{d}=5^{\circ}$ has a maximum efficiency rather than that of $\alpha \mathrm{d}=3^{\circ}$ and $\alpha \mathrm{d}=$ $8^{\circ}$ at nozzle-to-throat spacing to throat diameter ratio $X=1$ for all tested driving pressure from 1.0 to 2.5 bar by a step 0.5 bar. When the angle increases to $\alpha_{d}=8^{\circ}$ the losses due to separation increases but as the angle decreases to $\alpha_{d}=3^{\circ}$ the length of the diffuser increases and correspondingly the friction loss increases. 

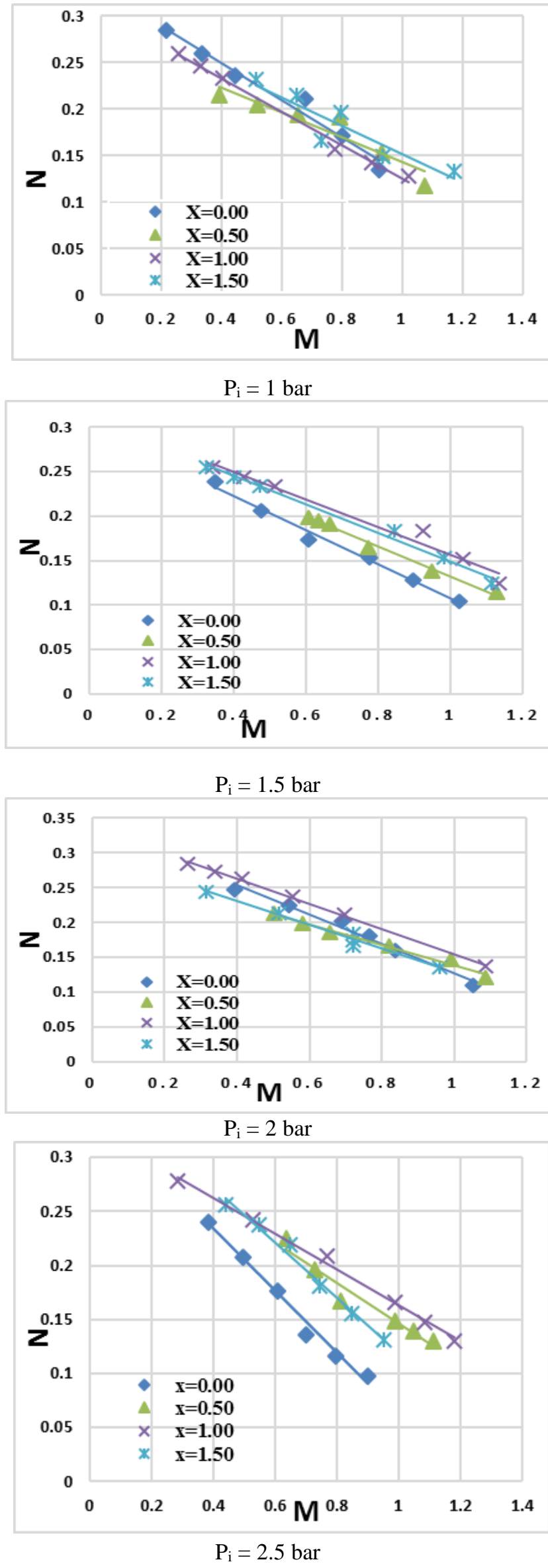

Fig. 4. Hed ratio vrs flow ratio $(N-M)$ curves at constat pressure and different nozzle to throat spacing $X ; \mathrm{R}=0.19, \alpha_{\mathrm{d}}=8^{\circ}$
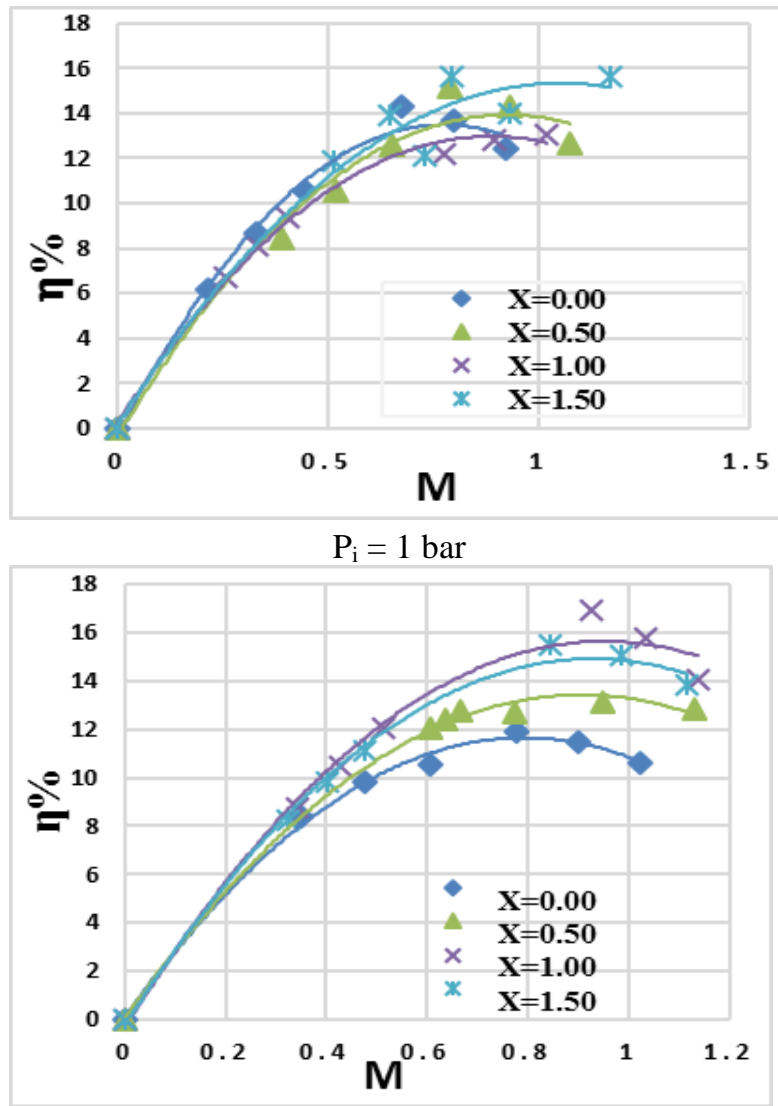

$\mathrm{P}_{\mathrm{i}}=1.5 \mathrm{bar}$

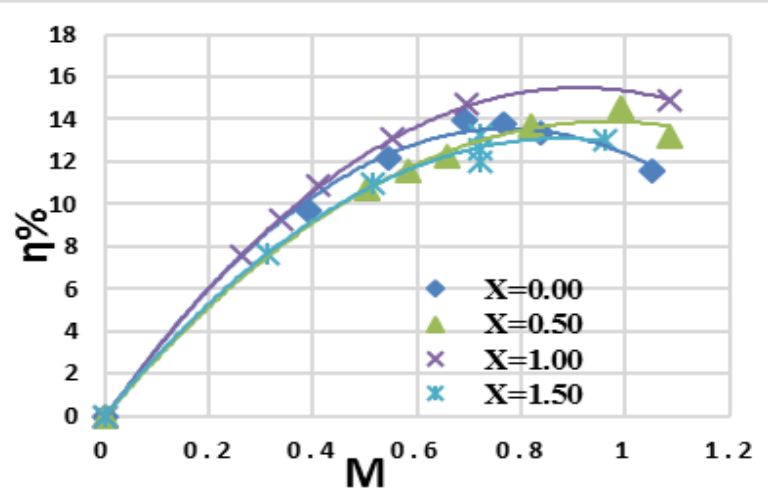

$\mathrm{P}_{\mathrm{i}}=2$ bar

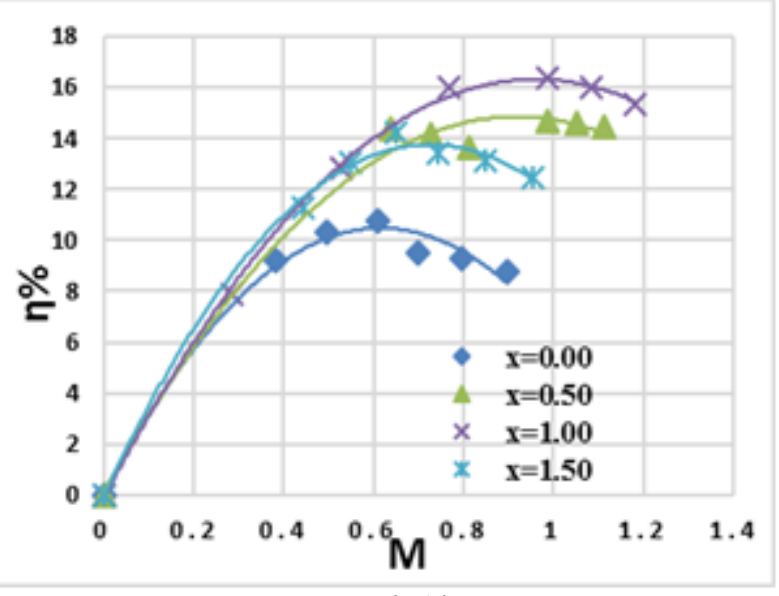

Fig. 5. Efficiency vrs flow ratio $(\eta-\mathrm{M})$ curves at constat pressure and different nozzle to throat spacing $\mathrm{X} ; R=0.19, \alpha_{d}=8^{\circ}$ 

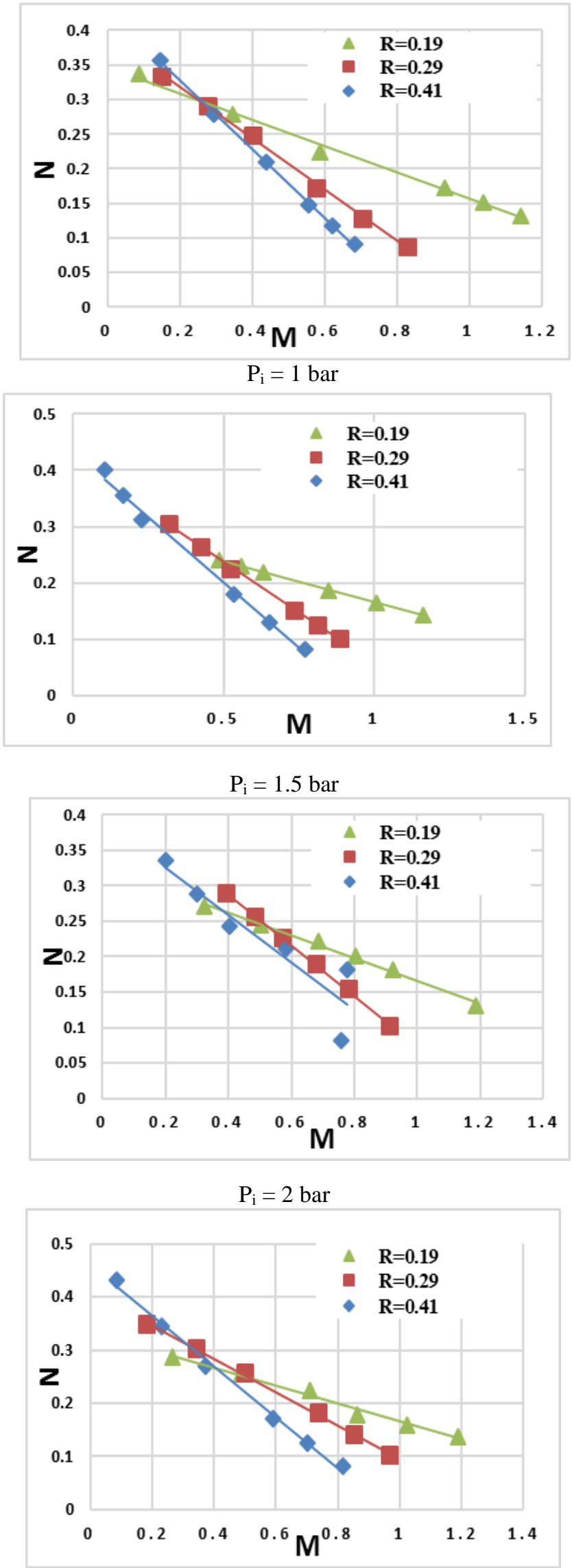

$$
\mathrm{P}_{\mathrm{i}}=2.5 \text { bar }
$$

Fig. 6. Hed ratio vrs flow ratio $(N-M)$ curves at constat pressure and different area ratio $R ; X=1, \alpha_{d}=5^{\circ} \mathrm{L}_{\mathrm{th}} / \mathrm{D}_{\mathrm{th}}=9.69$
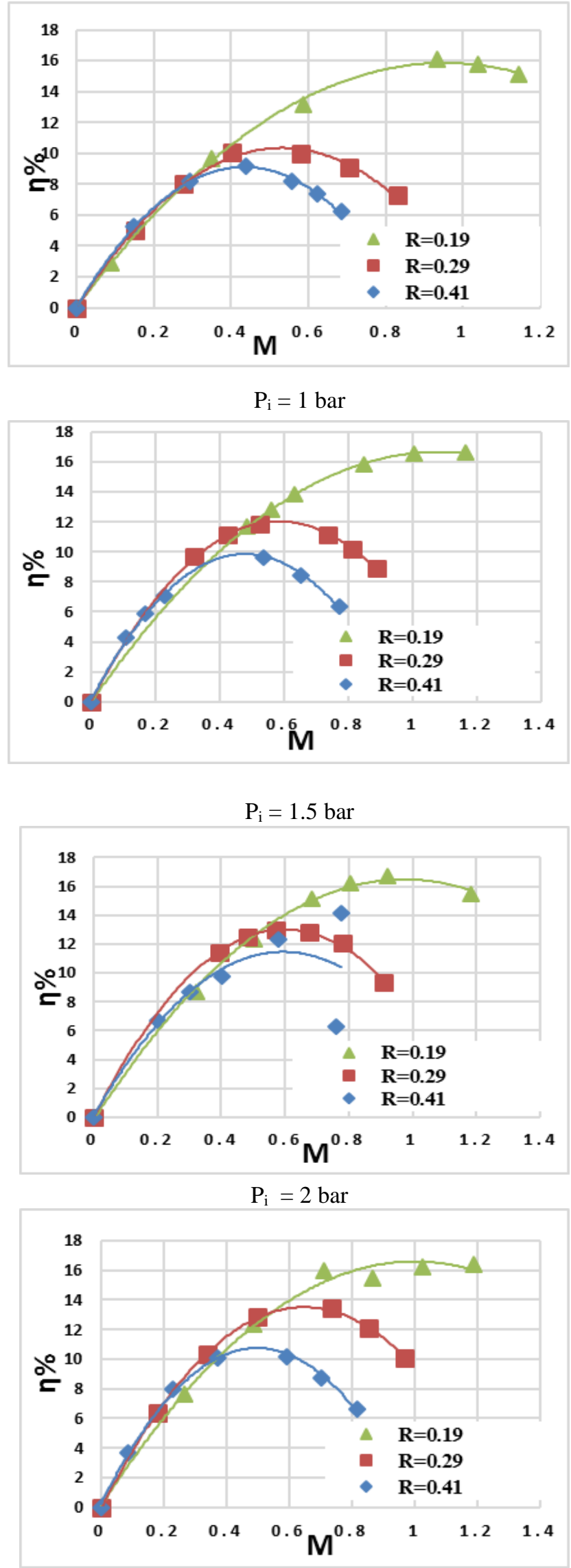

$$
\mathrm{P}_{\mathrm{i}}=2.5 \mathrm{bar}
$$

Fig. 7. Efficiency vrs flow ratio $(\eta-M)$ curves at constat pressure and different area ratio $R ; X=1, \alpha_{\mathrm{d}}=5^{\circ}, \mathrm{L}_{\mathrm{th}} / \mathrm{D}_{\mathrm{th}}=9.69$ 

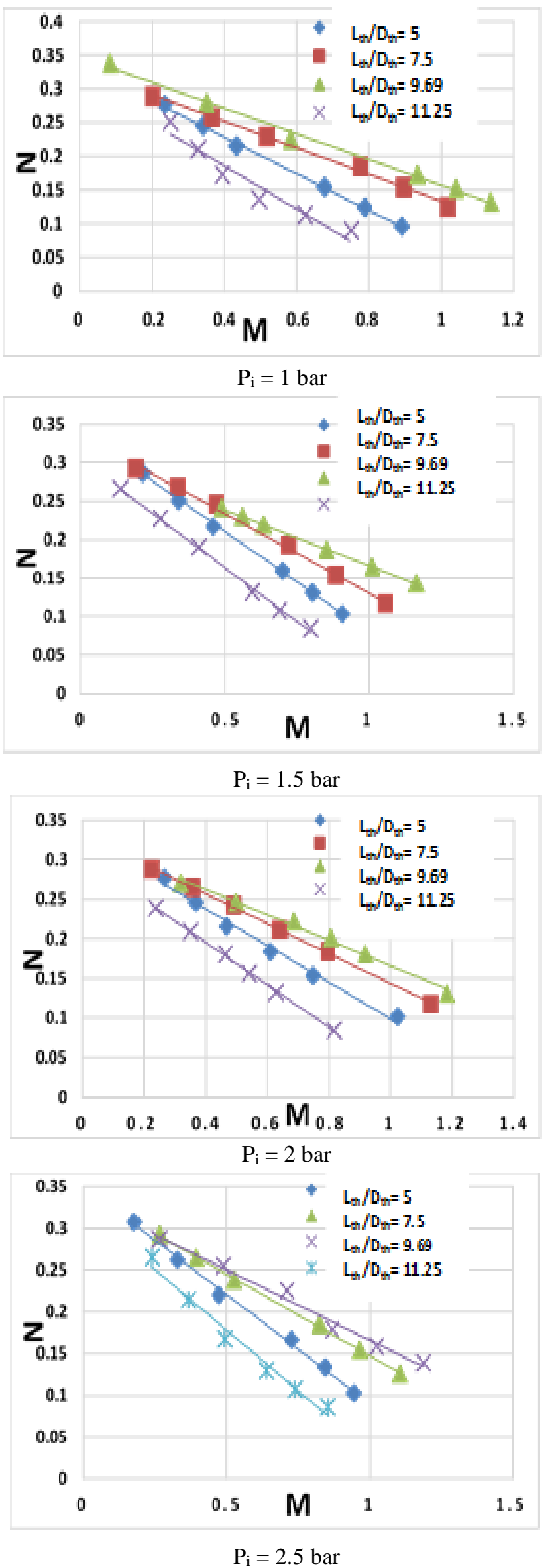

Fig. 8. jet pump performance (N-M) curves at constat pressure and different throat length to diameter ratio Lth/Dth

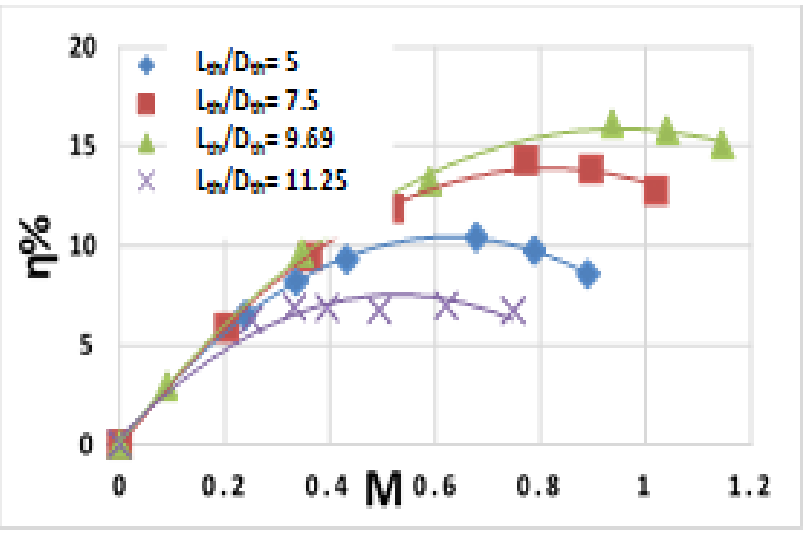

$P_{i}=1$ bar
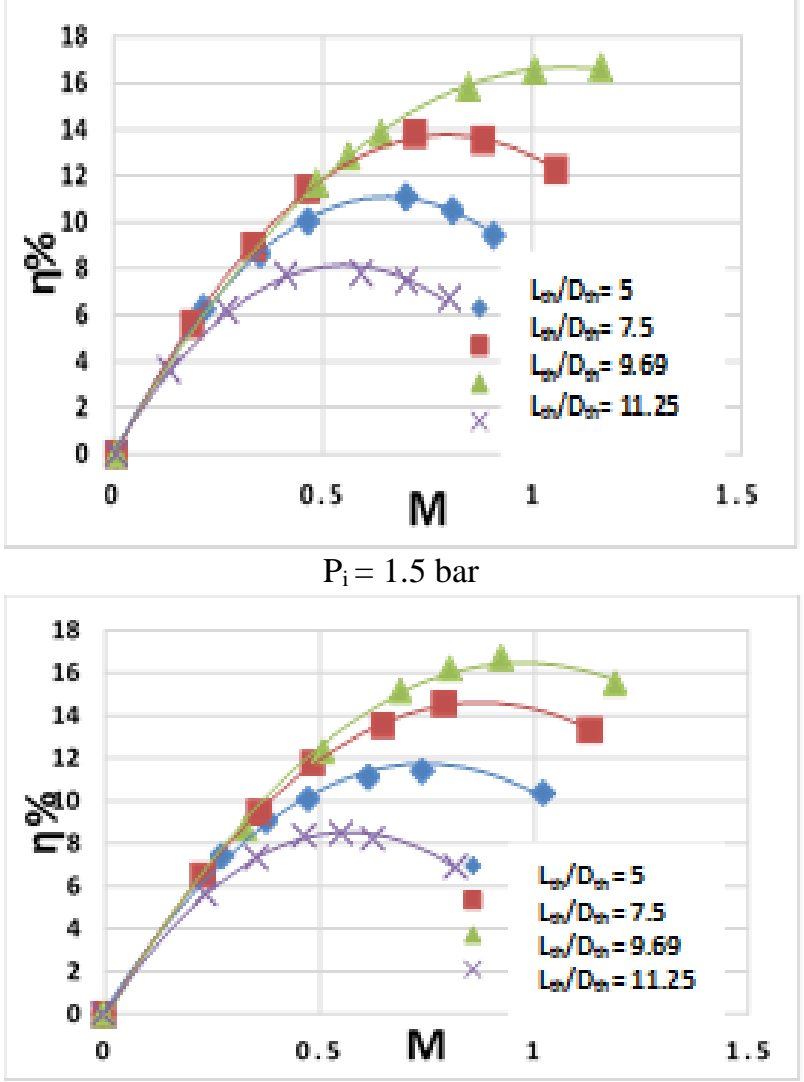

$\mathrm{P}_{\mathrm{i}}=2$ bar

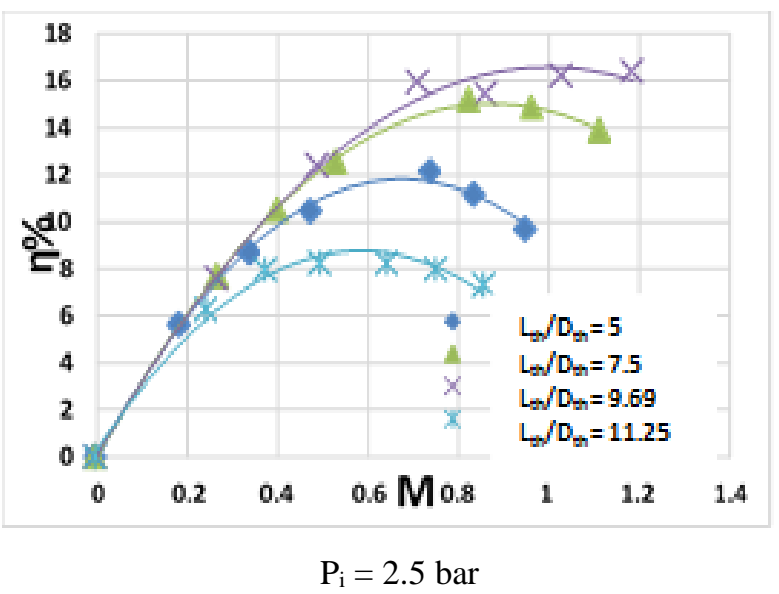

Fig. 9. jet pump performance $(\eta-M)$ curves at constat pressure and different throat length to diameter ratio Lth/Dth 


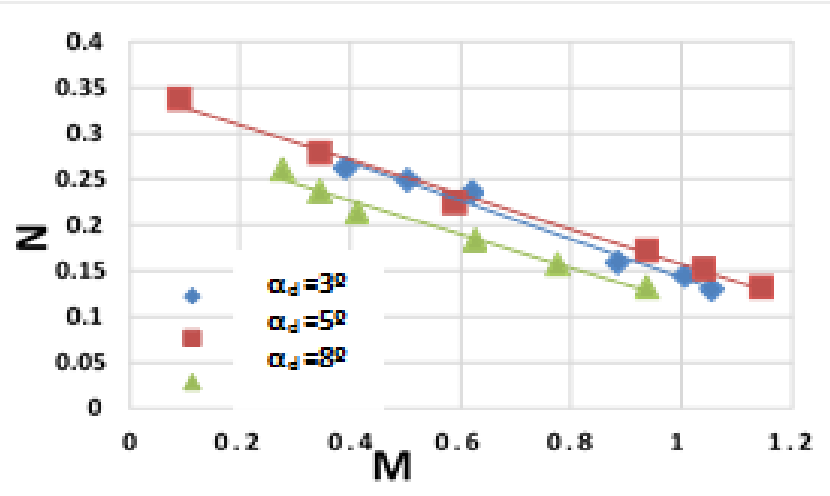

$P_{i}=1$ bar
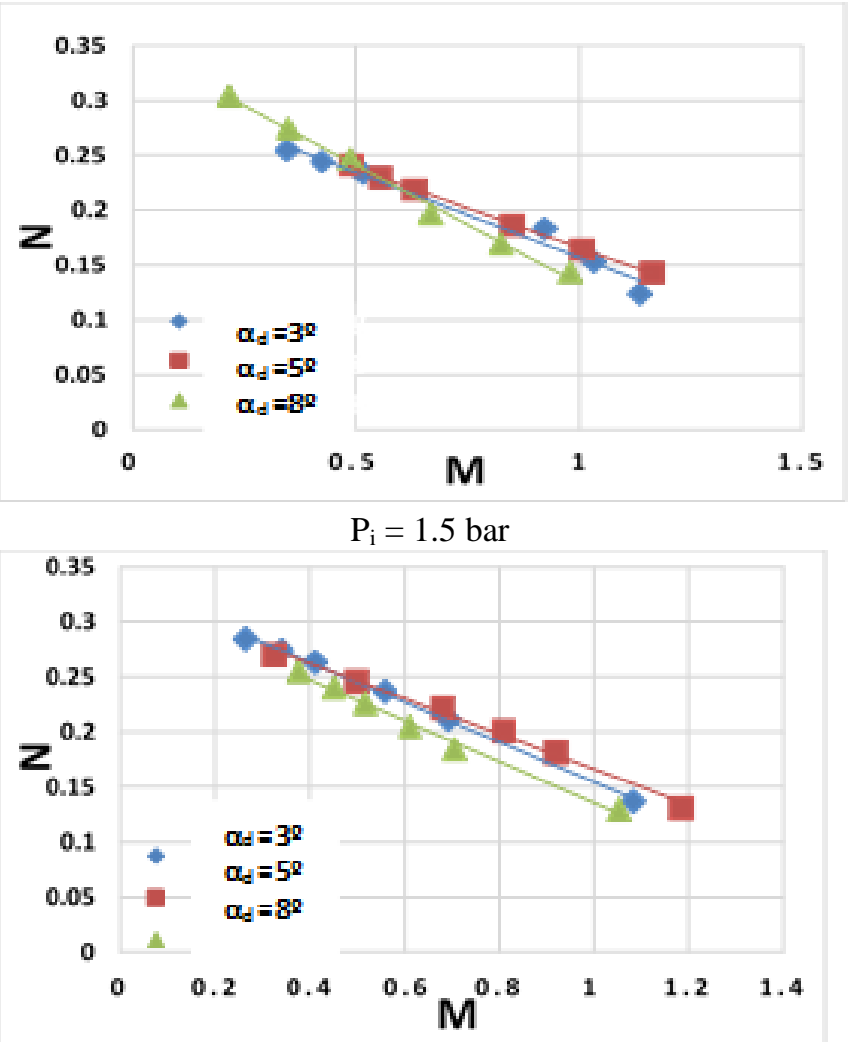

$$
P_{i}=2 \text { bar }
$$

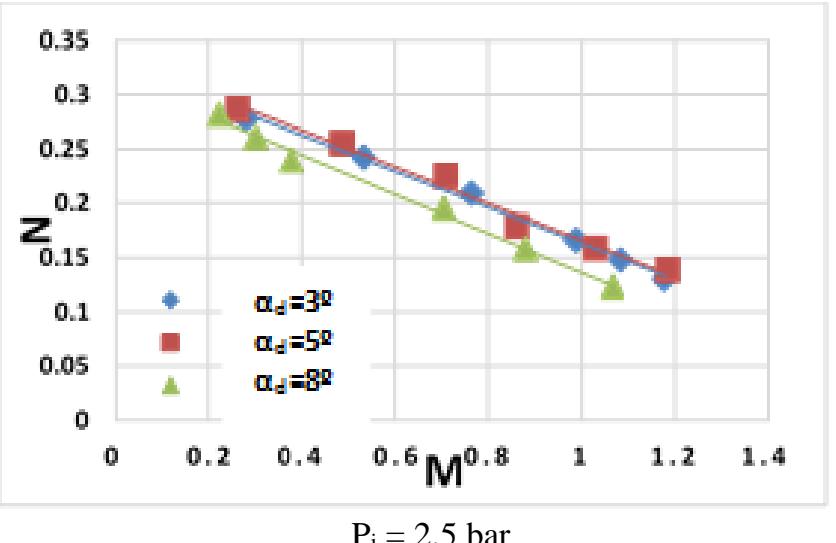

Fig. 10. jet pump performance $(N-M)$ curves at constant pressure and different throat length to diameter ratio $L_{t h} / D_{t h}$

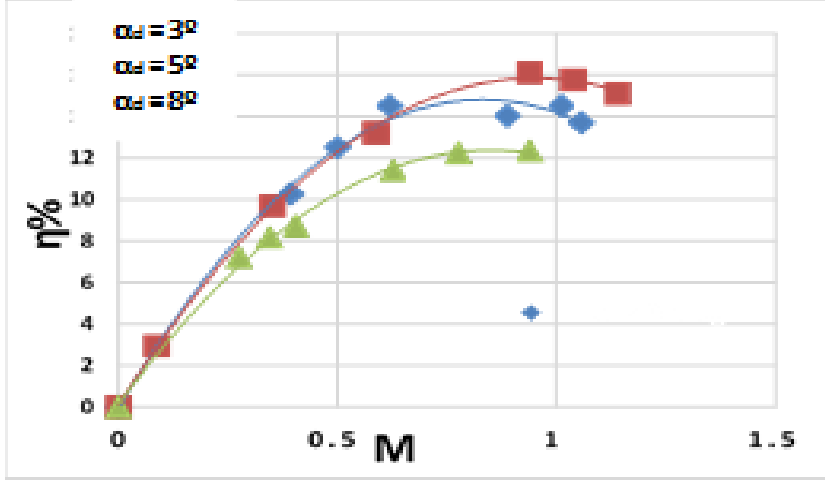

$\mathrm{P}_{\mathrm{i}}=1$ bar
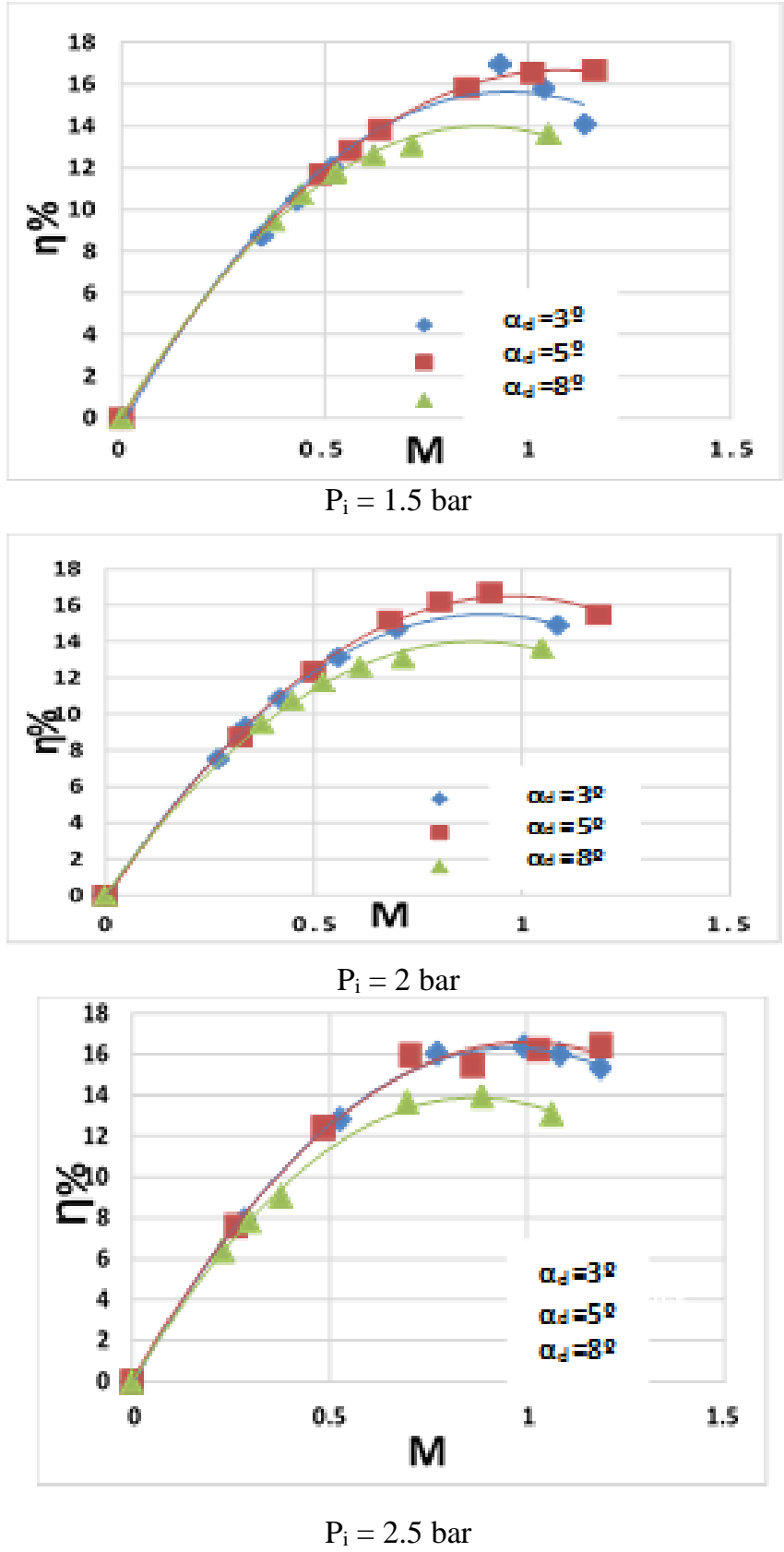

Fig. 11.jet pump performance $(\eta-M)$ curves at constat pressure and different throat length to diameter ratio $L_{t h} / D_{t h}$ 


\section{CFD MODELING}

In this section, the numerical setup in ANSYS Fluent will be presented. The pumps that are simulated are with an area ratio of $\mathrm{R}=0.19,0.29$ and 0.41 . A schematic drawing of the $1 / 1$-scale jet pump that is the basis of the simulation study; is shown in Figure 12. The 3-D solid modeling of the jet pump parts having various scales used in the CFD simulation are designed using SOLIDWORKS.

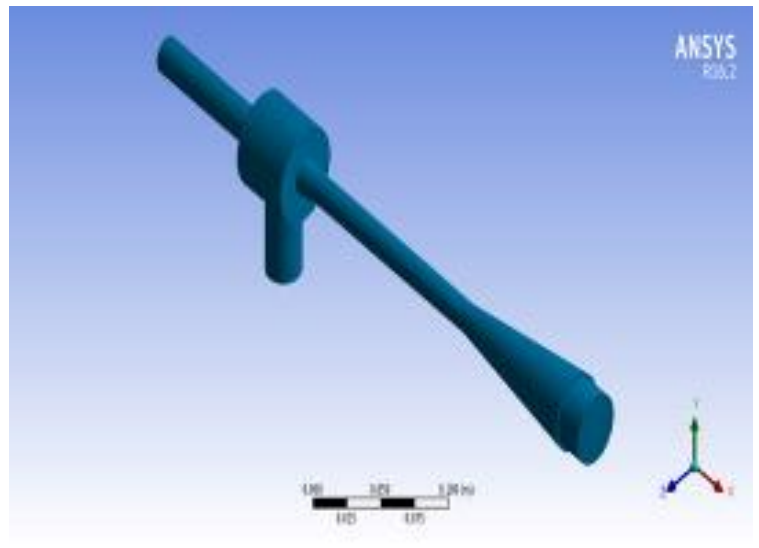

Fig. 12. Geometry of the complete jet pump

\section{A. Mathematical Equations}

The equations required to evaluate an isothermal Newtonian fluid flow are the continuity and the momentum balance equations. In addition, a turbulence model is also required. The continuity equation is given by the mass balance in one volume element.

$$
\frac{\partial}{\partial x_{j}}\left(\rho u_{j}\right)=0
$$

The momentum balance equation is.

$$
\frac{\partial}{\partial x_{j}}\left(\rho u_{i} u_{j}\right)=-\frac{\partial p}{\partial x_{i}}+\frac{\partial \tau_{i j}}{\partial x_{j}}
$$

The $\kappa-\varepsilon$ standard model uses the following equations for the transport of $\kappa$ and $\varepsilon$.

$$
\left[\frac{\partial\left(\rho u_{i} k\right)}{\partial x_{i}}\right]=\frac{\partial}{\partial x_{i}}\left[\left(\mu+\frac{\mu_{t}}{\sigma_{k}}\right) \frac{\partial k}{\partial x_{i}}\right]+P_{k}-\rho \varepsilon
$$

$\left[\frac{\partial\left(\rho u_{i} \varepsilon\right)}{\partial x_{i}}\right]=\frac{\partial}{\partial x_{i}}\left[\left(\mu+\frac{\mu_{t}}{\sigma_{s}}\right) \frac{\partial \varepsilon}{\partial x_{i}}\right]+\frac{\varepsilon}{k}\left(C_{s 1}-C_{s 2} \rho \varepsilon+C_{z 1} P_{s b}\right)$

Where, $\mathrm{C}_{\varepsilon 1}, \mathrm{C}_{\varepsilon 2}$, and $\sigma_{\kappa}$ are constants. $\mathrm{P}_{\kappa}$ is the turbulence production

\section{B. Grid Generation}

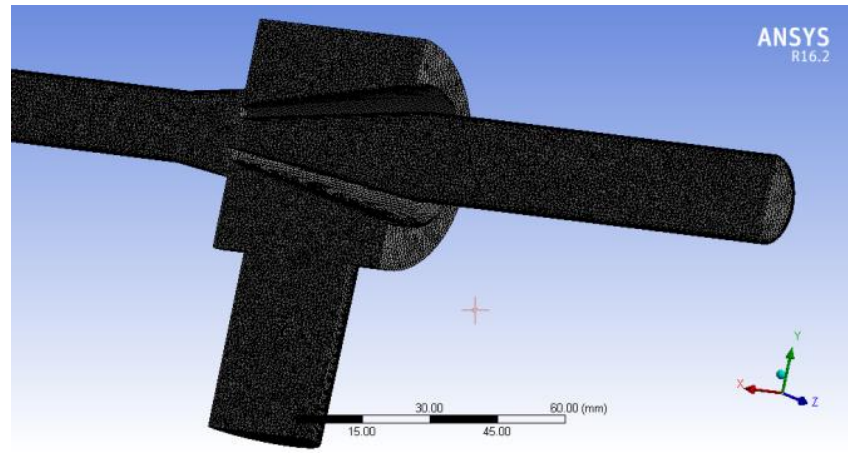

Fig. 13. Jet pump computational grid system

In the CFD study, the jet pump model geometry matched the experimental apparatus. Grid is mapped to the model geometry using grid-generating software. The grid size is optimized to be small enough to ensure that the CFD flow results are virtually independent of size, but large enough to ensure the model ran efficiently at an acceptable speed. For optimal meshing, the grid density is increase near the wall and in areas where flow gradients are steep. This is accomplished by applying weighting factors to increase the grid density at these areas. Figure 13 shows the grid of the whole domain, suction region, jet nozzle, mixing region, and diffuser region

\section{Mesh Quality}

In order to obtain a reliable and stable CFD results with acceptable accuracy measure, special considerations and quality measures are applied for the generated mesh before moving to the solver step. Three indicators are used in this study to report the quality of the mesh as shown in the following table.

Table 1 Quality measures for the mesh used in this study

\begin{tabular}{|l|c|c|}
\hline Quality parameter & Limitation & Mesh value \\
\hline Orthogonal quality & $(0-1)$ & 0.86487 \\
\hline Aspect ratio & $(1-100)$ & 1.8176 \\
\hline Skewness & $(0-1)$ & 0.2116 \\
\hline
\end{tabular}

\section{Mesh Independency}

A mesh independency test is done in this study to ensure that the final mesh produces a mesh independent solution. The grid convergence study is performed by developing four different meshes with different number of elements for the geometry of the jet pump . The number of elements simulated

\begin{tabular}{|c|c|c|c|c|}
\hline No. of mesh & 1 & 2 & 3 & 4 \\
\hline No. of Elements & $491 r .9$ & 514132 & 718177 & 1406954 \\
\hline No. of nodes & IY97YV & 168736 & 232056 & 441212 \\
\hline Suction velocity $\mathrm{m} / \mathrm{s}$ & $r, \cdot 1$. & 2.031 & 2.028 & 2.041 \\
\hline
\end{tabular}
for four meshes are summarized in Table 2.

Table 2 Mesh details 
Figure 14 illustrates the change in fluid outlet velocity tested using four different meshes. The test results show that there is a convergence between the results in mesh 3 and 4 and hence mesh 3 is selected they contain fewer elements to save time and get accurate result

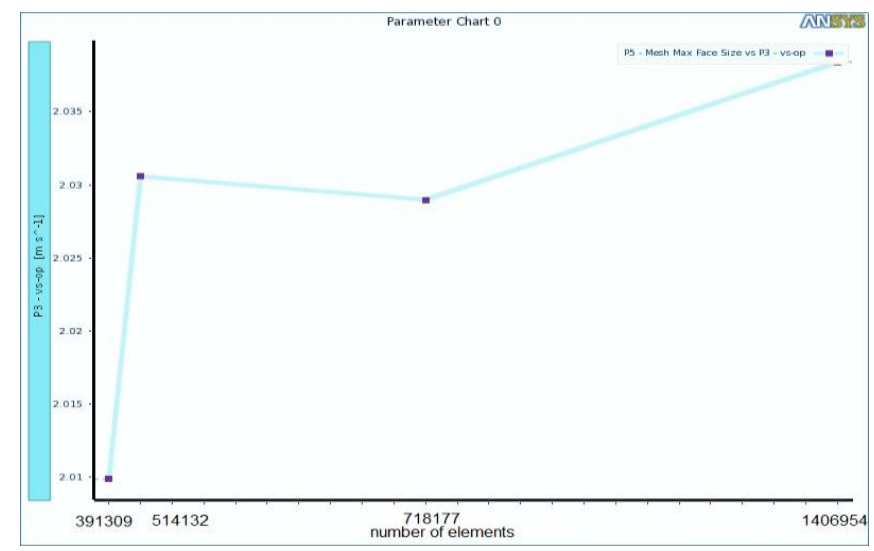

Fig. 14. Mesh independency curve

Table 3 gives a summary of the numerical mesh with 718,177 ; mesh 3, total number of elements.

Table 3: Summary of the numerical mesh

\begin{tabular}{|c|c|c|c|}
\hline Geometry & shape & element type & no of elements \\
\hline Jet pump & 3D & Tetrahedron & 718,177 \\
\hline
\end{tabular}

\section{E. Boundary Conditions}

The boundary conditions of fluid flow are the same as that of the experimental work. The total pressure of each of the primary and secondary streams giving the correct flow ratio at the inlet and the outlet static pressure is set as outlet boundary conditions. To reach a good convergence, the numbers of iterations are 150 for a time of calculation of about 3 hours on a core $\mathrm{i} 7$ processor, for each run.

\section{F. Results and Discussion}

In this section, the numerical results reflecting the effect of area ratio $R$ on the performance of jet pump. CFD simulations allowed getting information about flow phenomena appearing inside the pump. Obtained results in graphical form as a pressure and velocity distribution are shown on figures 15 and 16. These are exemplary results for the case motive pressure is 2.5 bars. Fig. 15 shows the velocity contour in jet pump for the area ratios of $R=0.19,0.3$ and 0.4 at motive pressure of 2.5 bar, $X=1$ and $\alpha_{d}=5^{\circ}$. It is clear from this figure that there is remarkable effect of changing the area ratio on velocity along the jet pump. Fig.16 shows the pressure contour in jet pump for the area ratio $R=0.19,0.29$ and 0.41 at motive pressure of 2.5 bar, $X=$ one and $\alpha_{\mathrm{d}}=5^{\circ}$. It is clear from the figure that changing the area ratio appreciably affect the pressure distribution along the jet pump. It may appear that when the area ratio increases, the pressure in suction line increases.
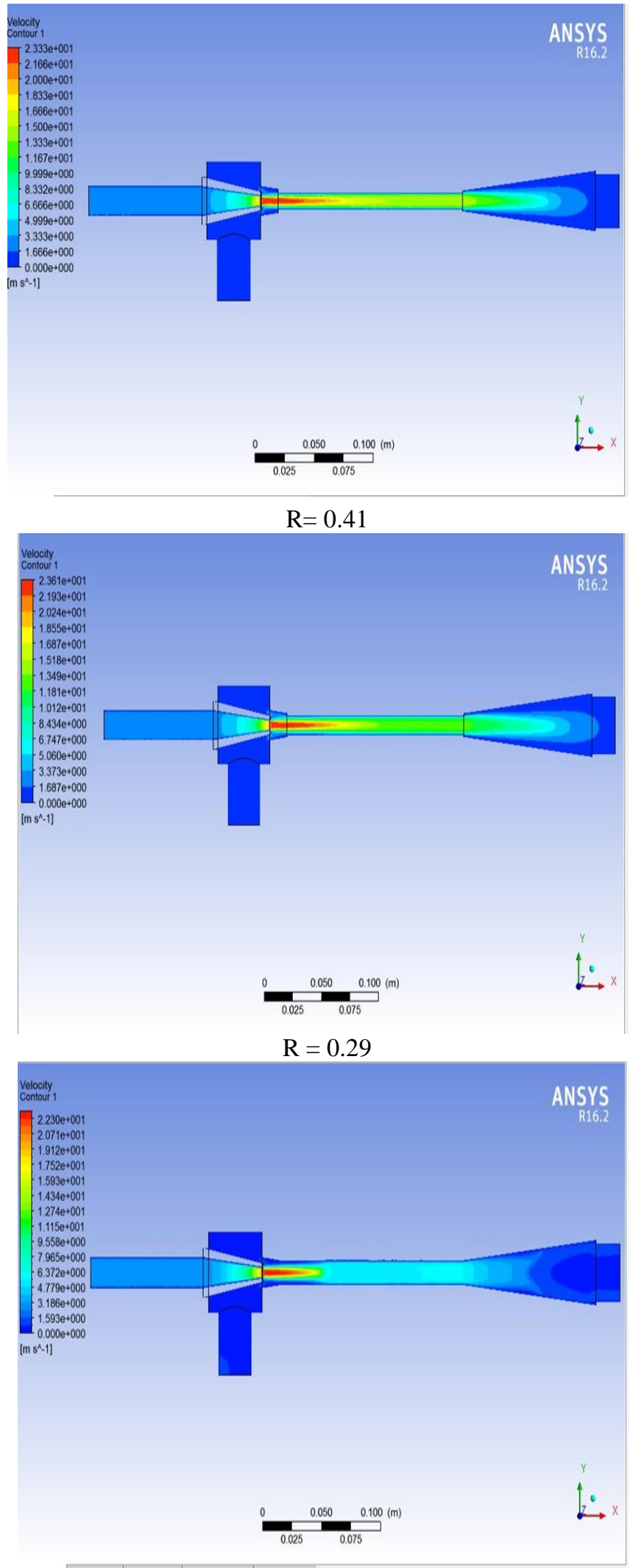

$$
\mathrm{R}=0.19
$$

Fig. 15. Velocity contour along the jet pump for different area ratio $(R=0.19,0.29$ and 0.41$) P_{i}=2.5$ bar, $X=1, L_{t h}=155$ and $\alpha_{d}=5^{\circ}$ 

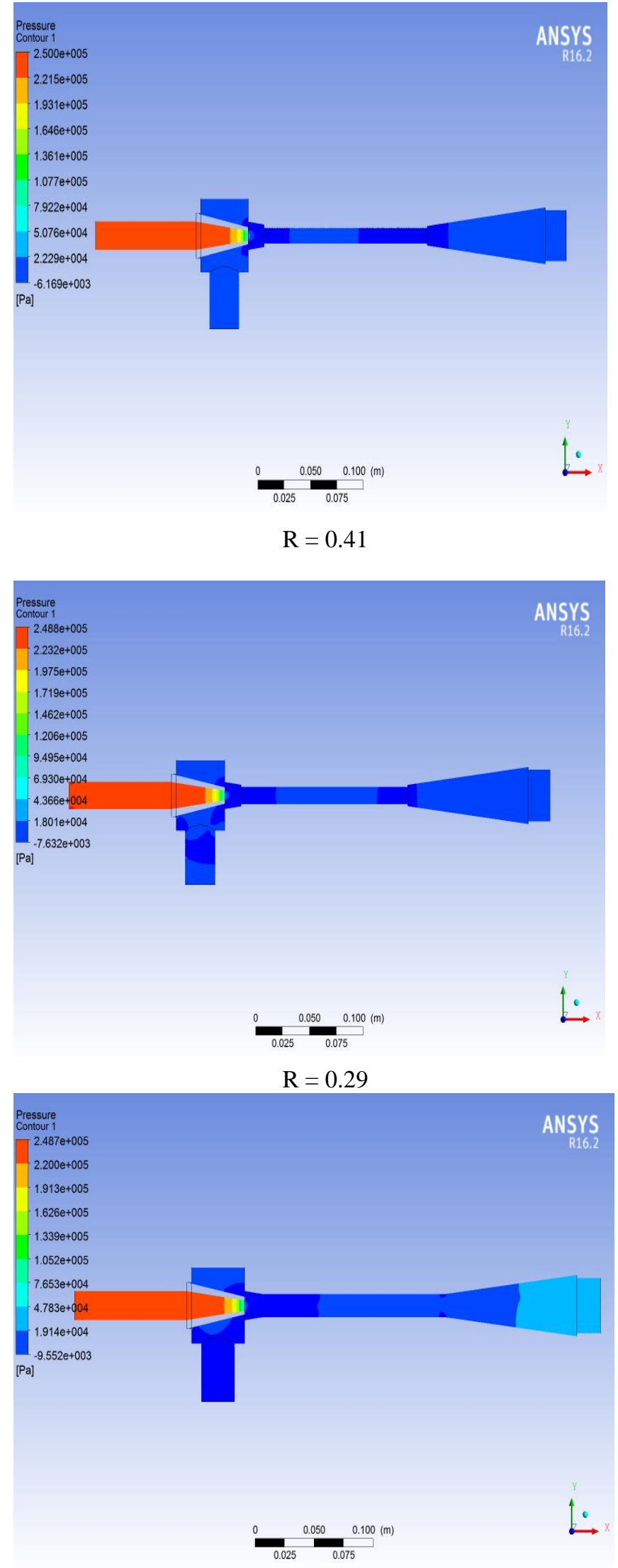

$\mathrm{R}=0.19$

Fig. 16. Pressure contour for different area ratio $(R=0.19,0.29$ and 0.41$) P_{i}=$ $2.5 \mathrm{bar}, X=1, L_{t h}=155 \mathrm{~mm}$ and $\alpha_{d}=5^{\circ}$
Figure 17(a) illustrates the comparison of static pressure distributions along the jet pump for different area ratios, for $R=0.19,0.29$ and 0.41 when the dimensionless nozzle distance $X=$ one, throat length ratio $L_{t h} / D_{t h}=9.69$ and diffuser angle $\alpha_{d}=5^{\circ}$. The trend of static pressure distributions takes the same behavior of the numerical values of static Pressure except for the negative pressure region in the beginning of the throat. It is clear from this figure that when increasing area ratio to 0.41 leads to a decrease of the negative pressure values at beginning of the throat.

Figure 17(b) illustrates the comparison of velocity distributions along the jet pump for different area ratio, for $R=$ 0.190 .29 and 0.41 when the dimensionless nozzle distance $X$ $=1$, throat length ratio $L_{t h} / D_{t h}=9.69$ and diffuser angle $\alpha_{d}=5^{\circ}$. The trend of velocity distributions takes the same behavior of the numerical values of $V$ except for the beginning of the throat. It is clear from this figure that when increasing area ratio to 0.41 leads to an increase of the velocity values at beginning of the throat.

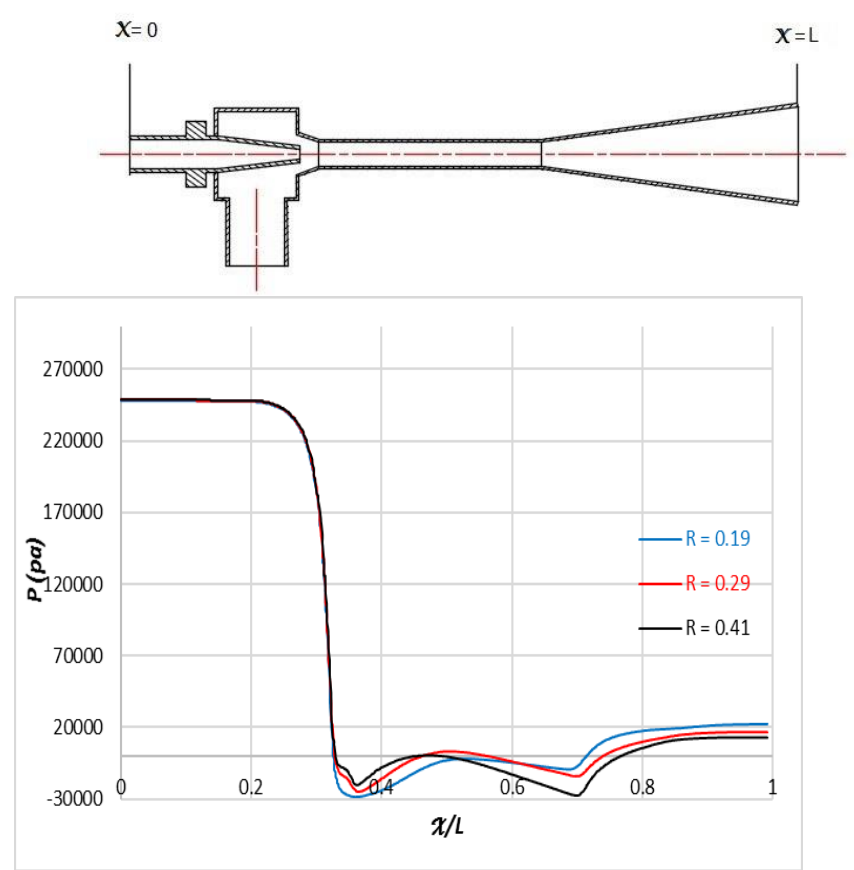

a)

static pressure along the jet pump

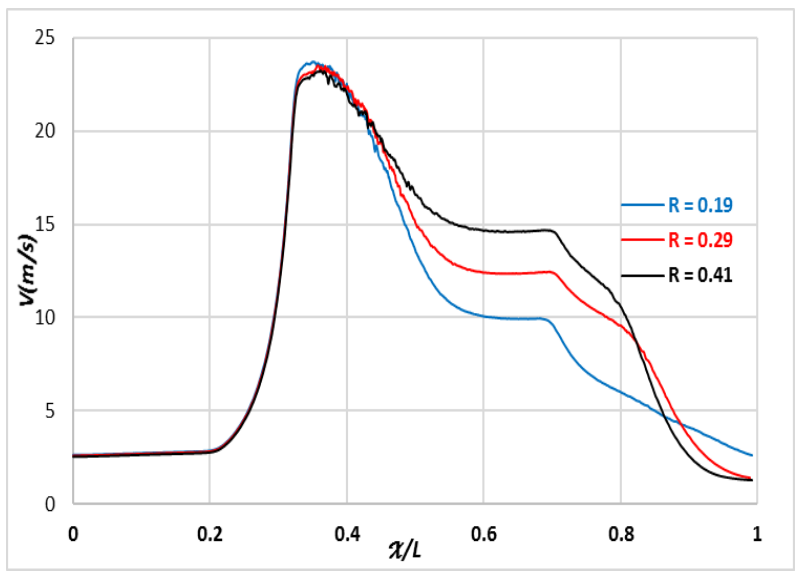

b)

velocity along the jet pump

Fig. 17. Comparison of pressure and velocity distributions along the jet pump 

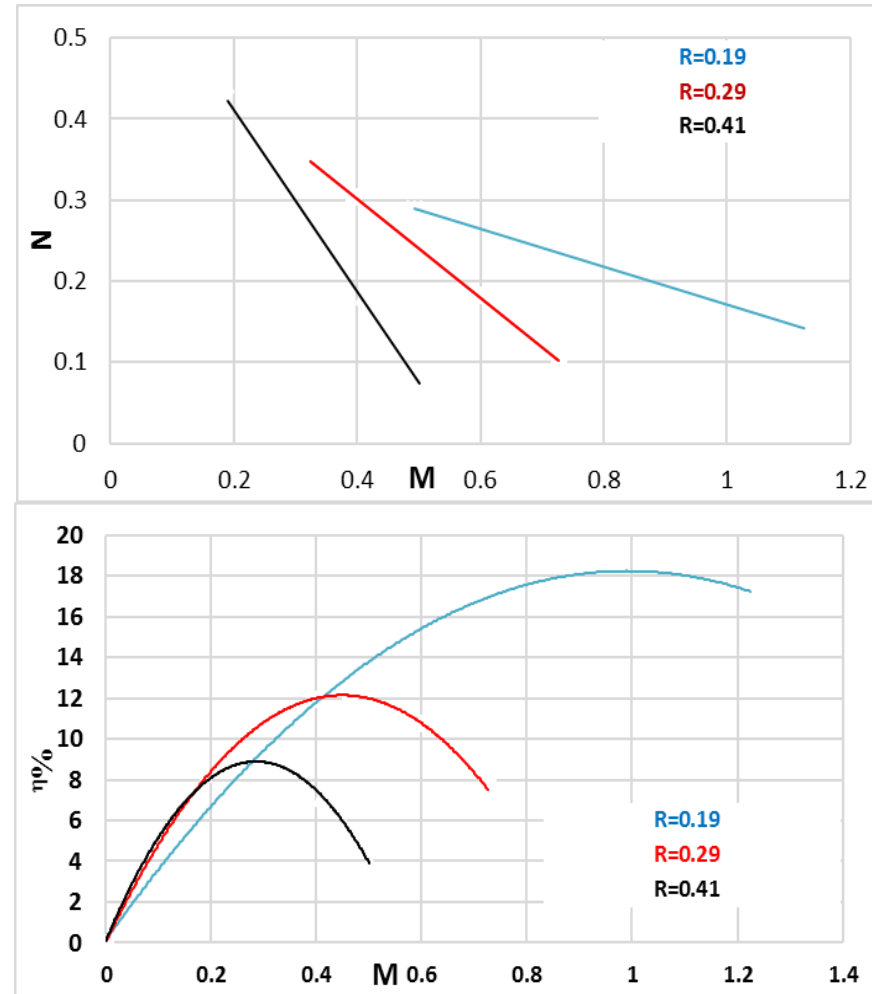

Fig. 18. Jet pump performance for different area ratios $P_{i}=2.5 \operatorname{barX}=1, L_{t h}=$ $155, \alpha_{d}=5^{\circ}$

Figure 18 illustrates the results (all data were obtained by ANAIS) of the effect of changing the area ratio on the performance of water jet pump under the following conditions: motive pressure $=2.5$ bar, nozzle to throat spacing to throat diameter ratio $\mathrm{X}=$ one, length of throat $=155 \mathrm{~mm}$ and diffuser semi cone angle $5^{\circ}$. At changing area ratio $R=$ $0.19,0.29$ and 0.41 , it clear from the figure for the same jet pump combination parts and increasing are ratio the efficiency decreased. The efficiency increases also with increasing the flow ratio. The highest values of efficiency are for are ratio $\mathrm{R}$ $=0.19$.

\section{ANALYTICAL ANALYSIS}

The flow in each part is described below; in figure 19, in this part all the equations are expressed. These equations were programmed in Mat lab to calculate jet pump performance.

Nozzle [10]

$$
\left(P_{i}-P_{0}\right)=Z\left(1+K_{\eta}\right)
$$

Throat Entry [10]

$$
\left(P_{s}-P_{0}\right)=Z S\left(1+K_{e n}\right)^{M^{2} / C^{2}}
$$

Throat [10]

$\left(P_{t}-P_{0}\right)=Z\left[2 R+\frac{25 M^{2} R^{2}}{1-R}-R^{2}\left(2+K_{t h}\right)(1+S M)(1+M)\right]($

Diffuser [10]

$\left(P_{d}-P_{t}\right)=Z_{b}^{2}(1+M)\left(1-K_{d i}-a^{2}\right)$
Pump efficiency $(\eta)$ is defined as the ratio of useful work rate on the secondary fluid (Q2) to The energy extracted from the primary liquid:

$$
\eta=\frac{Q_{2}\left(P_{d}-P_{2}\right)}{Q_{1}\left(P_{1}-P_{d}\right)}=M N
$$

Combining equations 13 to 16 , the theoretical head ratio of the liquid - liquid jet pump, $\mathrm{N}$ is

$$
N=\frac{2 R+\frac{25 M^{2} R^{2}}{1-R}-R^{2}\left(1+K_{t a}\right)\left(1+M^{2}-\left(\frac{M^{2}}{C^{2}}\right)\left(1+K_{\mathrm{sn}}\right)\right.}{\left(1+K_{n}\right)-2 R-\frac{25 M^{2} R^{2}}{1-R}+R^{2}\left(1+K_{t d}\right)\left(1+N^{2}+\left(\frac{M^{2}}{C^{2}}\right)\left(1+K_{\mathrm{sn}}\right)\right.}
$$

\section{A. Determination of Friction Loss Coefficients}

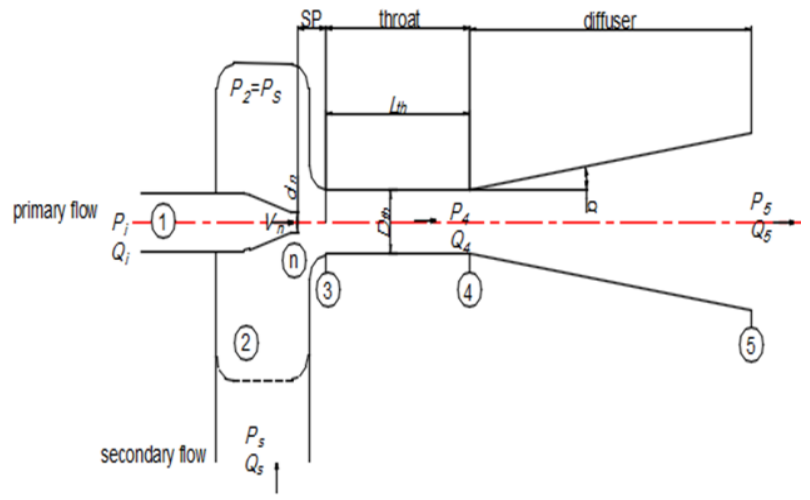

Fig. 19. Jet pump nomenclature.

The nozzle friction loss coefficient $\mathrm{K}_{\mathrm{n}}$; [5] is

$K_{n}=\frac{P_{1}-P_{n}}{V V_{n}^{2} / 2 g}-1$

Secondary inlet friction loss coefficient $\mathrm{K}_{\mathrm{en}}$; [5] is

$K_{\text {en }}=\frac{P_{2}-P_{3}}{V_{3}^{2} / 2 g}-1$

the diffuser friction loss coefficient $\mathrm{K}_{\mathrm{di}} ;$ [5] is

$K_{d i}=\frac{p_{4}-P_{5}}{V V_{4}^{2} / 2 g}$

A MATLAB computer program has been designed based on previously derived formulas and theoretical loss factors for all parts of the jet pump. 

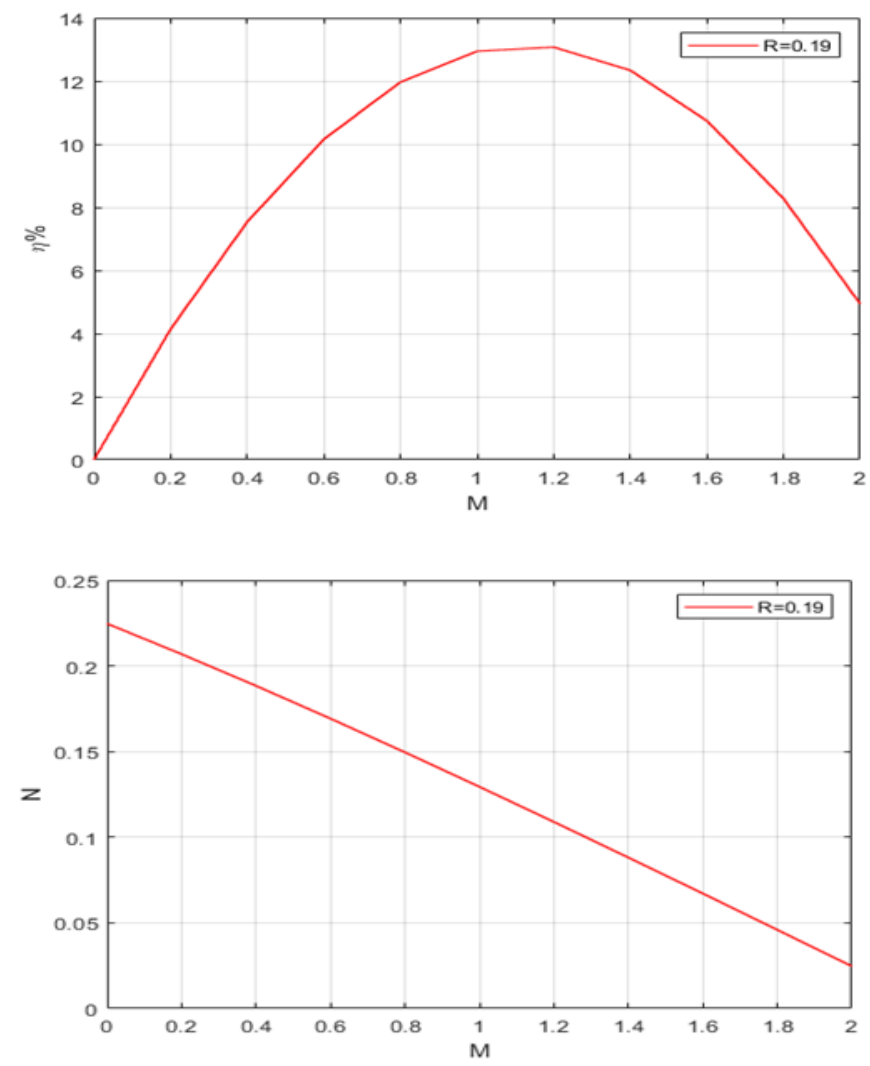

Fig. 20. Jet pump characteristic curve

Figure 20 illustrates the pump characteristic curve $\eta-M$ and $\mathrm{N}-\mathrm{M}$; obtained upon run of the above mentioned MATLAB program with the following jet pump configuration: area ratio of 0.19 , throat diameter and length of 16 and $155 \mathrm{~mm}$ respectively, diffuser angle $\alpha_{d}=8^{\circ}$ and nozzle distance ratio $X$ $=1$.

It is clear from the figure 20 that the theoretical equations can be used to find the characteristics curves of the jet pump, while specifying the friction coefficient values for the different parts of the jet pump, this facilitates the process of comparing the pumps without performing laboratory experiments.

\section{COMPARISON BETWEEN NUMERICAL, ANALYTICAL AND EXPERIMENTAL RESULTS OF THE CURRENT INVESTIGATION}

Figures 21 and 22 show the comparison between the experimental, analytical and numerical results of $\mathrm{M}-\mathrm{N}$ and $\eta-\mathrm{M}$ curves, for the following specifications: nozzle diameter of 7 $\mathrm{mm}$ the nozzle to throat spacing to throat diameter was $\mathrm{X}=1$, primary pressure of 2.50 bar, area ratio, $R=0.19$, throat length to diameter ratio of 9.69 and diffuser angle; $\alpha_{d}=5^{\circ}$.

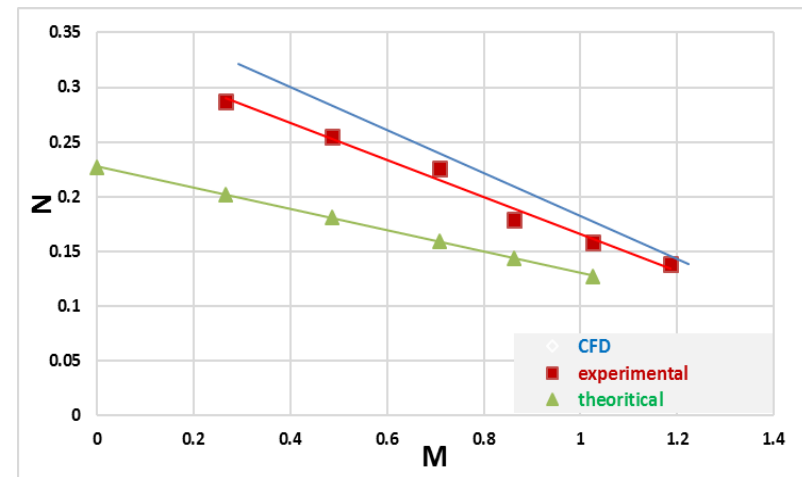

Fig. 21. Comparison of $(M-N)$ curve between the experimental and the theoretical results

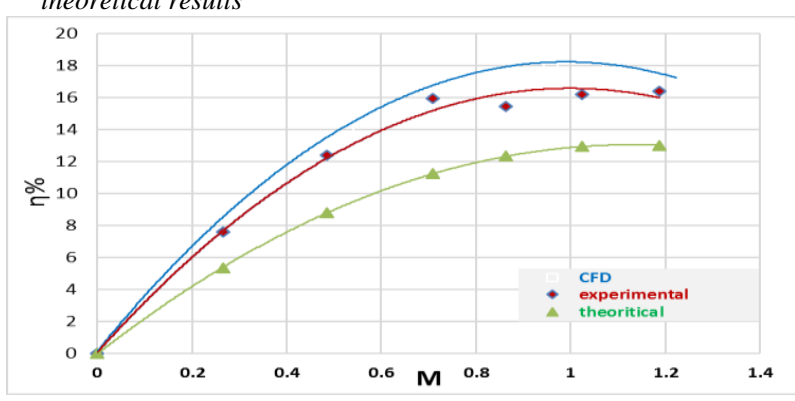

Fig. 22. Comparison of $(M-\eta)$ curve between the experimental and the theoretical results

It may be remarked from Figure 21 and 22 that the numerical value of efficiency is higher than the experimental value by about 3 percent. In all comparisons between the experimental and the numerical results, In all comparisons between the experimental and the theoretical results, It may be shows from the figures that the theoretical results are relatively close to the experimental results.

\section{CONCLUSIONS}

The main aim of the current study was to investigate the effect of operational and geometrical parameters on the jet pump performance and comparison between experimental and Theoretical (numerical and analytical) analysis.

The following conclusions are extracted:

- The optimum value of $X$ that gives the maximum efficiency is $X=1$.

- Increasing the driving pressure increases the flow ratio at maximum efficiency.

- The highest values of efficiency and head ratio are for area ratio of 0.19 at $X=1$

- the throat length to diameter ratio 9.69 had more efficiency

- the diffuser angle of $\alpha_{d}=5^{\circ}$ has maximum efficiency

- The optimum value for motive fluid pressure is about 2.5 bar

- An analytical equation to describe jet pump efficiency under various conditions has been derived there was a good agreement between the experimental results and the results obtained from the analytical equation. 
References

[1] Gosline, J.E., and O'Brien, M. P., "The Water Jet Pump", University of California Publications in Engineering, Vol. 3, No. 3, pp. 167-190, 1934.

[2] Mueller, N. H. G., "Water Jet Pump", Journal of Hydraulic Division, Vol. 90, No. HY 3, pp.83-113, 1964.

[3] SATISH P.M., A STUDY OF WATER JET PUMPS. India: University of Baroda. 1963

[4] Reddy, Y. R. and Kar, S., "Theory and Performance of Water Jet Pump", Journal of Hydraulic Division, Vol. 94, No. Hy5, pp. 1261$1281,1968$.

[5] Sanger, N. L. "Noncavitating Performance of Two Low-Area - Ratio Water Jet Pumps Having Throat Lengths of 7.25 Diameters", NASA TND-4445, 1968.

[6] Zandi, I. and Govatos, G., Jet Pump Slurry Transport, Hydrotransport $1,1^{\text {st }}$ International Conference on the Hydraulic Transport of Solids in Pipes, BHRA, Paper L2, pp. L2-17: L2-32, September, 1970.

[7] Grupping, A.W., Coppes, J.L.R., and Groot, J.G., "Fundamentals of Oil Well Jet Pumping", SPE Production Engineering, pp.9-14, February 1988.

[8] Hatziavrarnidis, D. T., "Modeling and Design of Jet Pumps", SPE .Prod. Engineering, pp.413-419, 1991.

[9] El-Sawaf I. A. Halawa M.A., Younes M. A. and Teaima I.R.., Study of The Different Parameters That Influence on The Performance of Water Jet Pump. Fifteenth International Water Technology Conference, IWTC, 2011.

[10] Karassik I.J., Messina J.P., Cooper P., and Heald C.C. Pump Handbook. New York: McGraw-Hill; 3 edition.

[11] El-Otla, F. M., El-Sawaf, I. A. and El-Ghandour, M. Performance of a Central-Type Jet Pump. (II Experimental Study on Water Flow), 8th International water conference, Alexandria, Egypt, pp.535-551, 2004.

[12] Frank N.L., McDonnel G.A., and Kegel M.F. The Effects of Jet Angle and Geometry on the Performance of the Jet Assisted Air Lift Pump. Fisheries \& Aquatic Sciences Technical Report No. 1062 .November 1981

[13] Gugulothu S.K., Srinivas B.S. and Eshwaraiah P. Experimental Analysis of Single Nozzle Jet Pump with varying Area ratio. Gitam University, Hyderabad, Telangana, India.2014

[14] Saker A.A. and Hassan H.Z. study of the different factors that influence jet pump performance Open Journal of Fluid Dynamics, 2013, 3, 44-49

[15] Kisbocskoi, L., "About the Dimensioning of Water-Jet Pumps", Proceeding of Sixth Conference on Fluid Machinery, Vol.1, Paper 60, pp.567-574, 1979 .

[16] Meakhail,T. and Teaima, I., "Experimental and numerical studies of the effect of area ratio and driving pressure on the performance of water and slurry jet pumps", J Mechanical Engineering Science 226(9) 2250-2266 IMechE, 2011.

[17] Meakhail,T. and Teaima, I., "A Study of the Effect of Nozzle Spacing and Driving Pressure on the Water Jet Pump Performance", International Journal of Engineering Science and Innovative Technology (IJESIT) Volume 2, Issue 5, September 2013

[18] Sheha, A. A., Nasr, M., Wahba, E.M and Hosien, M.A Computational and Experimental Study on the Water-Jet Pump Performance, Journal of Applied Fluid Mechanics, Vol. 11, No. 4, pp. 1013-1020, 2018., 2018.

[19] El-Sawaf I. A. Halawa M.A., Younes M. A. and Teaima I.R.., Study of The Different Parameters That Influence on The Performance of Water Jet Pump. Fifteenth International Water Technology Conference, IWTC, 2011.

[20] I. ANSYS, ANSYS® Academic Research Mechanical, Release 16.2, Help System, Coupled Field Analysis Guide. 2017.

[21] Aldas K., and Yapici R. Investigation of effects of scale and surface roughness on efficiency of water jet pumps using CFD. Engineering Applications of Computational Fluid Mechanics Vol. 8, No. 1, pp. 1425 (2014)

[22] Pedroso M.C., Bannwart A.C. and Morales R.E. computational fluid dynamics applied to jet pumps. 23rd ABCM International Congress of Mechanical Engineering December 6-11, 2015, Rio de Janeiro, RJ, Brazil

[23] Naik B.R. and Patel S.M. The Effect of Venturi Design on Jet Pump

Performance. Journal for Research, Volume, 02 Issue, June 2016 
Faculty of Energy Engineering - Aswan University - Aswan - Egypt 